\title{
Physical fitness attenuates the genetic predisposition to obesity in children and adolescents
}

\author{
Pâmela Ferreira Todendi ${ }^{1}$ (D) | Caroline Brand ${ }^{2}$ (D) \\ Anelise Reis Gaya $^{3}$ (D) | Cesar Agostinis-Sobrinho4 (D) | Marilu Fiegenbaum ${ }^{5}$ (D) | \\ Ryan Donald Burns $^{6}$ (D) | Andréia Rosane de Moura Valim² (D) | Cézane Priscila Reuter ${ }^{2}$ (C)
}

${ }^{1}$ Graduate Program in Endocrinology, Universidade Federal do Rio Grande do Sul, Porto Alegre, Brazil

${ }^{2}$ Graduate Program in Health Promotion, University of Santa Cruz do Sul (UNISC), Santa Cruz do Sul, Brazil

${ }^{3}$ School of Physical Education, Physiotherapy and Dance, Federal University of Rio Grande do Sul (UFRGS), Porto Alegre, Brazil

${ }^{4}$ Faculty of Health Sciences, Klaipeda University, Klaipeda, Lithuania

${ }^{5}$ Department of Basic Health Sciences, Federal University of Health Sciences of Porto Alegre (UFCSPA), Porto Alegre, Brazil

${ }^{6}$ Department of Health, Kinesiology, and Recreation, University of Utah, Salt Lake City, Utah

\section{Correspondence}

Cézane Priscila Reuter, Graduate Program in Health Promotion, University of Santa Cruz do Sul (UNISC), Av. Independência, 2293 - Postal code: 96816-501; Bairro Universitário, Santa Cruz do Sul, Rio Grande do Sul, Brazil.
Obesity is an important risk factor associated with non-communicable cardiometabolic diseases. Previous studies have indicated that children and adolescents with a predisposed genetic risk for obesity could benefit from an active lifestyle, but there are no studies investigating whether physical fitness moderates the association of genetics and obesity. The aim of this study was to verify the moderating role of physical fitness in the relationship between genetic risk score (GRS) and body mass index (BMI) in children and adolescents. This cross-sectional study was carried out with 1471 children and adolescents, aged between 6 and 17 years from Santa Cruz do Sul, Brazil. Weight and height were assessed to determine BMI. Physical fitness components (cardiorespiratory fitness [CRF], lower limb strength [LLS], upper limb strength, and abdominal strength) were evaluated. The GRS was based on previously associated obesity single-nucleotide polymorphism rs9939609 (FTO), rs6548238 (TMEM18), and rs16835198 (FNDC5). Moderation analyses were tested using linear regression models, and the interactions were represented by physical fitness components X GRS (categorical variable). All analyses were adjusted for skin color/ ethnicity, sex, and sexual maturation. Significant interactions for CRF $(P=0.041)$, LLS $(P=0.041)$, and abdominal strength $(P=0.046) \mathrm{X} 5$ and 6 risk alleles with BMI were found only in adolescents. In addition, there was evidence that fitness components attenuated the high genetic predisposition to high BMI. Physical fitness components are moderators in the relationship between GRS and BMI in adolescents. These findings highlight the need for interventions targeting to improve this aspect, which is an important health indicator in all ages.

\section{K E Y W O R D S}

adolescence, childhood, genetics, obesity, physical fitness

\section{1 | INTRODUCTION}

Obesity is a chronic disease considered one of the most important risk factors associated with the development of several non-communicable cardiometabolic diseases. ${ }^{1-3}$ Several studies have been shown an elevated prevalence of obesity among children and adolescents, with approximately $30 \%$ being classified as overweight or obese. As a consequence of the global obesity 
pandemic, children and adolescents have shown early development of type 2 diabetes, hypertension, metabolic syndrome, depression, and other risk factors associated. ${ }^{1,4,5}$

A global public health challenge is to understand the key causes of the early development of overweight and obesity. ${ }^{2}$ Unhealthy behaviors play an essential role as modifiable determinants of obesity, such as sedentary behavior, sleep abnormalities, low engagement in daily physical activity, and socio-environmental factors such as parents and peers. ${ }^{5,6}$ These behaviors could be primary determinants of early obesity incidence. ${ }^{3,7}$ Conversely, genetic predisposition to obesity is the a non-modifiable risk factor in obesity development with a heritability ranging from $40 \%$ to $70 \%{ }^{8,9}$

Previous studies have indicated that children and adolescents with a predisposed genetic risk for obesity could benefit from a healthy and active lifestyle. ${ }^{8,9}$ Additionally, youth without genetic predisposition could become obese with poor lifestyle behaviors. ${ }^{8,9}$ Within this context, adequate levels of physical activity could be important effect modifiers because of the dose-response association with obesity prevalence..$^{10,11}$ Physical fitness has a dose-response relationship with physical activity engagement and is considered an essential physical characteristic for the protection against the development of diseases across the lifespan. ${ }^{12}$ Recently, many authors have highlighted the relevance of obesity and physical fitness as a primary risk factor associated with several diseases in children. ${ }^{12}$

Among the genetic aspects of obesity, genetic polymorphisms have been previously associated with the early development of obesity, accelerating weight gain over childhood, including rs9939609 (FTO), rs6548238 (TMEM18), and rs16835198 (FNDC5). ${ }^{8,9}$ In adults, physical fitness attenuated the influence of genetic predisposition on obesity risk. ${ }^{13}$ However, according to our knowledge, there are no studies investigating these inter-relationships in children and adolescents. Although, evidence indicates that FTO polymorphism is associated with obesity and that physical activity reduces the risk of obesity even in the presence of genetic risk factors. ${ }^{14,15}$

Thus, considering the role of lifestyle behaviors on the genetic predisposing of obesity and the consequences of early obesity development in children and adolescents, the aim of this study was to examine the potential moderating role of physical fitness in the relationship between a genetic risk score and body mass index (BMI) in a sample of Brazilian children and adolescents.

\section{2 | METHODS}

\subsection{Study design and sample}

This cross-sectional study was carried out with 1471 children and adolescents, aged between 6 and 17 years, which were randomly selected from 25 schools from Santa Cruz do Sul, Rio Grande do Sul, Brazil. The selected children and adolescents belonged to the Schoolchildren's Health study: Phase III, conducted between 2014 and 2015. This study is a lifestyle education program developed by a multidisciplinary team of nutritionists, nurses, pharmacists, physiotherapists, and physical educators from University of Santa Cruz do Sul (UNISC). This study meets the ethical standards established by the Declaration of Helsinki and was approved by the Research Ethics Committee of the UNISC (number 714 216/14). Also, parents or guardians signed the free and informed consent form.

\section{2 | Measures}

Data were collected between 2014 and 2015 in the facilities of UNISC. Students and/or parents were interviewed face-toface, and a questionnaire was completed. The questionnaire comprised of items regarding students' demographic data (ie, age, skin color/ethnicity, and sex). Brazil is a country with great admixture. ${ }^{16}$ For this reason, participants' color/ethnicity determination was based on an evaluation of the following phenotypic characteristics: skin color in the medial part of the arm; color and texture of hair; and the shape of the nose and lips. ${ }^{17}$

Height and weight were measured on the anthropometric scale with a coupled stadiometer (Filizola $\left.{ }^{\circledR}\right)$. BMI was calculated by dividing body mass (in kilograms) by height (in square meters). Tanner's criteria were considered to evaluate sexual maturation. ${ }^{18}$ The researcher explained the pictures with the different stages and the children/adolescents indicated the picture accordingly to their current stage, considering breast development (girls), genital development (boys), and pubic hair (both). Therefore, five stages of sexual maturation were considered and subsequently categorized into four classes: pre-pubertal (stage I), initial development (stage II), continuous maturation (stages III and IV), and matured (stage V).

The evaluation of physical fitness was applied according to the procedures of Projeto Esporte Brasil, ${ }^{19}$ which consists in a battery applied to determine physical fitness components in children and adolescents, widely used in Brazil. ${ }^{20,21}$ Cardiorespiratory fitness (CRF) was assessed by the six-minute walk/run test. Children and adolescents were instructed to achieve the greatest number of turns, running or walking, in a six-minute period. The test was conducted on an outside sports track with the perimeter marked with cones and the floor indicating the distance (in meters) that was traveled. The number of laps successfully completed and the additional distance achieved for the ones unable to complete a full lap at the end of the test was calculated. CRF was then determined by multiplying the number of laps by meters covered. The 
sit-up test was used to assess abdominal strength, in which the total number of sit-ups performed for 1-minute was verified. Lower limb strength (LLS) was assessed through the long jump test. For the LLS, a measuring tape fixed to the floor was used, in which the individual positioned behind the starting point with joined feet should jump as far as possible. The better of two attempts was recorded. To evaluate upper limb strength (ULS), a measuring tape was fixed to the floor. Participants were positioned seated, with legs together, leaning their body against the wall, after flexing their arms they were instructed to throw the medicine ball as far as possible. Two attempts were made and the longest distance was recorded.

\section{3 | Genetic risk score}

EDTA-anticoagulated whole blood was used for DNA extraction by the salting-out method. ${ }^{22}$ DNA was then quantified using a NanoDrop 2000c spectrophotometer unit (Thermo Scientific). The genotyping of polymorphisms TMEM18 rs6548238, FTO rs9939609, and FNDC5 rs16835198 was performed using Taqman $^{\mathrm{TM}}$ allelic discrimination assays (Applied Biosystems) in StepOne Plus® equipment, according to the manufacturer's instructions. TaqMan ${ }^{\mathrm{TM}}$ assays C_29311887_10 (rs6548238), C_30090620_10 (rs9939609) and C_34204885_10 (rs16835198) and Master Mix PCR Universal were purchased from Applied Biosystems. The genetic risk score (GRS) was based on previously associated obesity single-nucleotide polymorphism (SNP) rs9939609 (FTO), rs6548238 (TMEM18), and rs16835198 (FNDC5). $^{23}$ The unweighted GRS was constructed using a genotypic score based on the number of unfavorable alleles (those associated with higher levels of BMI $\mathrm{Z}$-score and waist circumference) that were carried by each subject for each of the three SNP. ${ }^{24}$

\subsection{Statistical analysis}

Descriptive data are presented as means, standard deviations, and frequencies for count data. Independent two-tailed $t$ tests were used to examine differences between boys and girls and between children and adolescents. The effect size (Cohen's d) was also calculated. Moderation analyses were tested using multiple linear regression models, through the PROCESS macro for the Statistical package for Social Sciences (SPSS) version 24.0 (IBM Corp). The following models were applied: (a) associations between physical fitness components (CRF, LLS, ULS, and abdominal strength) with BMI; (b) associations between genetic risk scores with BMI; (c) interactions between physical fitness components and genetic risk scores (3-4 risk alleles; $\geq 5$ risk alleles). This interaction is the result of multiplication between the effects of independent and moderator variables, presented in our work as genetic risk score categories $\mathrm{X}$ physical fitness components, respectively.

The genetic risk score was fitted into the regression models as a categorical variable, and the category $\leq 2$ risk alleles were considered the reference group for all analyses. Additionally, the Johnson-Newman technique was applied to establish the moderation point, in which physical fitness components were classified according to tertiles. Thus, this technique indicates the relationship between the independent (genetic risk score) and dependent (BMI) variables in the low, medium, and high levels of the moderator variable (physical fitness). All analyses were adjusted for skin color/ ethnicity, sex, and sexual maturation. The probability value $P<0.05$ was considered to be significant for all analyses.

Multiple linear regression was used as a statistical test for sample calculation on $\mathrm{G}^{*}$ Power 3.1 program (HeinrichHeine-Universität), considering the following parameters: test power $(1-\beta)=0.95$, a significance level of $\alpha=0.05$, and effect size of 0.03 . The number of predictors considered was six, and the minimum sample size was established as 702 in each age group (children and adolescents).

\section{3 | RESULTS}

Table 1 presents the characteristics of the sample. Boys presented more favorable BMI scores than girls. Also, children and adolescents' males presented a better performance in all physical fitness components than females. Adolescents presented higher mean values for all continuous variables compared to children.

The moderator role of physical fitness in the relationship between genetic risk score and BMI in adolescents is presented in Table 2. An inverse association between CRF and BMI was observed in children $(P<0.001)$ and adolescents $(P<0.001)$. Also, adolescents with $\geq 5$ risk alleles were more likely to present a high BMI, compared to those with $\leq 2$ risk alleles $(P=0.002)$. Regarding interactions, it was found to be significant between CRF, LLS, and abdominal strength $\mathrm{X} \geq 5$ risk alleles with BMI only in adolescents, indicating that these components of physical fitness are moderators in the relationship between genetic risk score and BMI.

For a better comprehension of interactions, we applied the Johnson-Newman technique in order to establish the level of CRF that adolescents should achieve to attenuate the positive relationship between BMI and the genetic risk alleles (Figure 1). It was found a significant association between $\geq 5$ risk alleles and BMI in low $(742.40 \mathrm{~m})$ and medium (909.00 m) CRF (Figure 1A), low (1.13 m) and medium $(1.37 \mathrm{~m})$ LLS (Figure 1B), and in low (17 repetitions) and medium (25 repetitions) abdominal strength (Figure 1C). 
TA B LE 1 Participants' characteristics

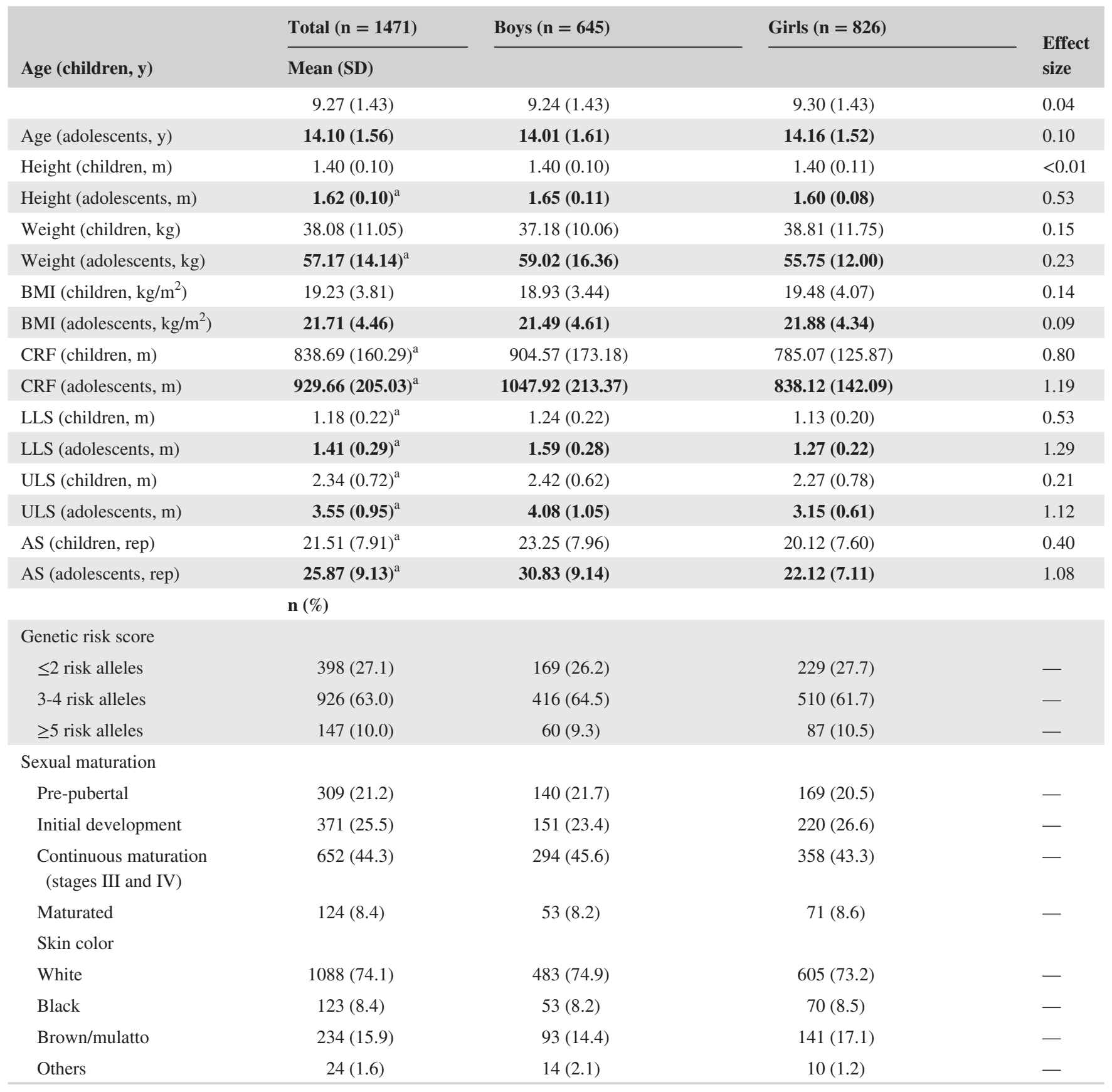

Note: Effect size for the difference between children and adolescents scores: Age (Total: 3.22; Boys: 3.12; Girls: 3.28); Height (Total: 2.20; Boys: 2.37; Girls: 2.11); Weight (Total: 1.49; Boys: 1.58; Girls: 1.42); BMI (Total: 0.59; Boys: 0.62; Girls: 0.57); CRF (Total: 0.49; Boys: 0.73; Girls: 0.39); LLS (Total: 0.15; Boys: 1.38; Girls: 0.66); ULS (Total: 1.42; Boys: 1.89; Girls: 1.27); AS (Total: 0.51; Boys: 0.88; Girls: 0.27).

Bold denotes differences between children and adolescents scores using the independent $t$ test $(P<0.05)$.

Abbreviations: AS, abdominal strength; BMI, Body mass index; CRF, Cardiorespiratory fitness; LLS, Lower limb strength; SD, Standard deviation; ULS, Upper limb strength.

${ }^{\mathrm{a}}$ Denotes differences between boys and girls scores using the independent $t$ test $(P<0.05)$.

Additionally, adolescents that accomplished the CRF and LLS test more than $1150 \mathrm{~m}$ and $1.70 \mathrm{~m}$, respectively, and executed more than 34 repetitions on abdominal strength test, had their BMI scores attenuated. Since that was no interaction between CRF and genetic risk score in children, Johnson-Newman technique was not applied.

\section{4 | DISCUSSION}

The main findings of the present study indicate that CRF, LLS, and abdominal strength are moderators in the relationship between a genetic risk score and BMI in adolescents. Also, it was found a significant association between 
TA B LE 2 Moderation of physical fitness in the relationship between genetic risk score and body mass index in children and adolescents

\begin{tabular}{|c|c|c|c|c|c|c|}
\hline & \multicolumn{6}{|c|}{ Body mass index $\left(\mathrm{kg} / \mathrm{m}^{2}\right)$} \\
\hline & $\boldsymbol{\beta}$ & CI $(95 \%)$ & $P$ & $\boldsymbol{\beta}$ & CI $(95 \%)$ & $P$ \\
\hline \multicolumn{7}{|c|}{ Cardiorespiratory fitness } \\
\hline $\mathrm{CRF}(\mathrm{m})$ & -0.007 & -0.010 to -0.003 & $<0.001$ & -0.006 & -0.008 to -0.003 & $<0.001$ \\
\hline $\begin{array}{l}\leq 2 \text { risk } \\
\text { alleles }\end{array}$ & Ref & & & Ref & & \\
\hline $\begin{array}{r}\text { 3-4 risk } \\
\text { alleles }\end{array}$ & 1.730 & -1.599 to 5.059 & 0.308 & -1.775 & -5.004 to 1.454 & 0.281 \\
\hline $\begin{array}{l}\geq 5 \text { risk } \\
\text { alleles }\end{array}$ & 1.097 & -3.704 to 5.897 & 0.654 & 7.238 & 2.586 to 11.890 & 0.002 \\
\hline $\begin{array}{l}\mathrm{CRF} \mathrm{x} \geq 5 \\
\text { risk alleles }\end{array}$ & -0.001 & -0.007 to 0.004 & 0.680 & -0.005 & $-\mathbf{0 . 0 1 0}$ to $-\mathbf{0 . 0 0 1}$ & 0.041 \\
\hline \multicolumn{7}{|c|}{ Lower limb strength } \\
\hline $\operatorname{LLS}(\mathrm{m})$ & -3.941 & -6.381 to -1.501 & 0.002 & -4.190 & -6.246 to -2.134 & $<0.001$ \\
\hline \multicolumn{7}{|c|}{ Genetic risk score } \\
\hline $\begin{array}{l}\leq 2 \text { risk } \\
\text { alleles }\end{array}$ & Ref & & & Ref & & \\
\hline $\begin{array}{r}\text { 3-4 risk } \\
\text { alleles }\end{array}$ & 2.293 & -1.188 to 5.773 & 0.196 & -0.699 & -4.085 to 2.687 & 0.685 \\
\hline $\operatorname{ULS}(\mathrm{m})$ & 1.450 & 0.479 to 2.422 & 0.003 & 1.496 & 0.840 to 2.152 & $<0.001$ \\
\hline \multicolumn{7}{|c|}{ Genetic risk score } \\
\hline $\begin{array}{r}\leq 2 \text { risk } \\
\text { alleles }\end{array}$ & Ref & & & Ref & & \\
\hline $\begin{array}{r}\text { 3-4 risk } \\
\text { alleles }\end{array}$ & 0.994 & -1.563 to 3.551 & 0.446 & -0.813 & -3.484 to 1.856 & 0.550 \\
\hline $\begin{array}{l}\geq 5 \text { risk } \\
\text { alleles }\end{array}$ & 2.328 & -0.894 to 5.549 & 0.156 & 4.617 & 0.454 to 8.780 & 0.030 \\
\hline $\begin{array}{l}\text { ULS x 3-4 } \\
\text { risk alleles }\end{array}$ & -0.340 & -1.415 to 0.736 & 0.535 & 0.279 & -0.460 to 1.018 & 0.459 \\
\hline $\begin{array}{l}\text { ULS } x \geq 5 \\
\text { risk alleles }\end{array}$ & -0.972 & -2.281 to 0.338 & 0.146 & -0.548 & -1.620 to 0.524 & 0.316 \\
\hline \multicolumn{7}{|c|}{ Abdominal strength } \\
\hline $\begin{array}{l}\text { AS } \\
\text { (repetitions) }\end{array}$ & -0.174 & -0.243 to -0.105 & $<0.001$ & -0.118 & -0.184 to -0.051 & 0.001 \\
\hline \multicolumn{7}{|c|}{ Genetic risk score } \\
\hline $\begin{array}{l}\leq 2 \text { risk } \\
\text { alleles }\end{array}$ & Ref & & & Ref & & \\
\hline
\end{tabular}


TABLE 2 (Continued)

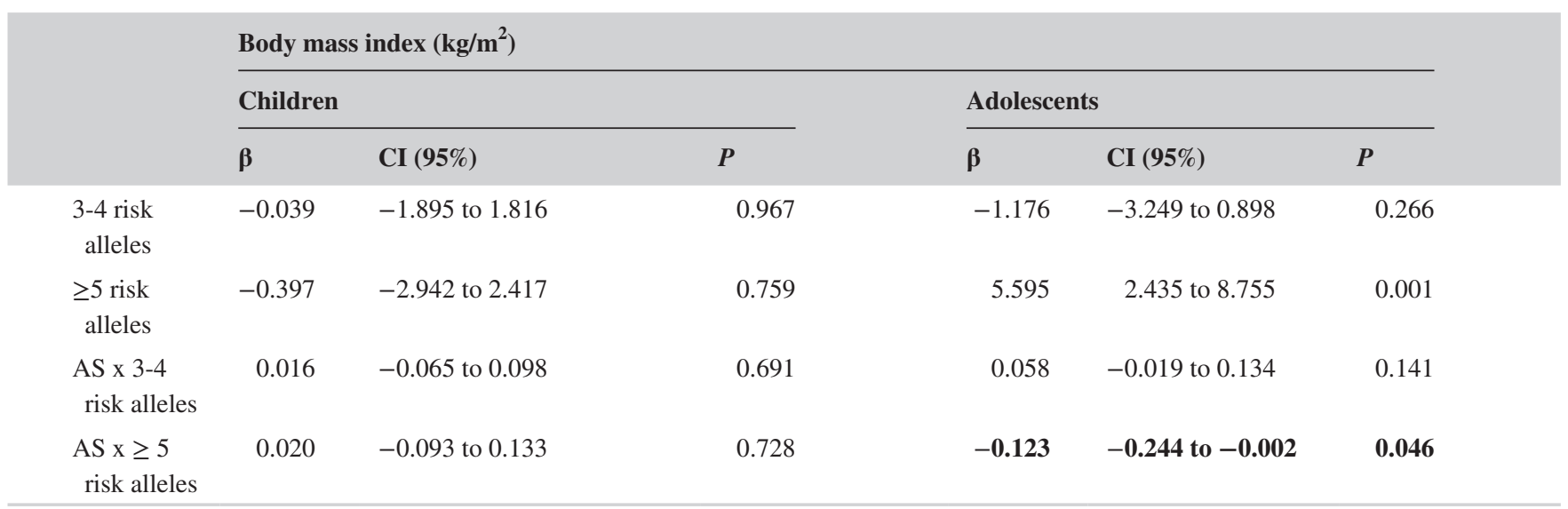

Note: All analyses were adjusted for skin color/ethnicity, sex, and sexual maturation.

Abbreviations: AS, Abdominal strength; CRF, Cardiorespiratory fitness; LLS, lower limb strength; m, Meters; Ref, Reference group; ULS, Upper limb strength. Bold denotes significant interactions.

5-6 genetic alleles and BMI only in adolescents with low and medium CRF, LLS, and abdominal strength. This suggests that BMI scores were attenuated among those adolescents with high levels of specific physical fitness components, even considering the genetic predisposition to obesity. Therefore, it was found that adolescents should accomplish more than $1150 \mathrm{~m}$ on the CRF test, $1.70 \mathrm{~m}$ in the LLS test, and perform more than 34 repetitions in the abdominal strength test.

To our knowledge, there are no data investigating the moderating role of physical fitness in the relationship between a genetic risk score and BMI in children and adolescents. The present findings highlight the relevance of achieving an appropriate physical fitness in youth, especially for adolescents that present a genetic predisposition to obesity. The results indicated that physical fitness was not capable of attenuating higher BMI in younger children, probably because in this phase they cannot achieve a high level of CRF, LLS, and abdominal strength. Indeed, the guidelines from which the procedures of the tests were followed classify the subjects in a healthy zone according to age and sex. According to this guideline, the appropriate levels for health on CRF, LLS, and abdominal strength are only achieved in adolescents. ${ }^{19}$

Systematic reviews have indicated that youth obesity is an independent risk factor for several well-established adult cardiometabolic risk factors, such as high levels of blood pressure and cholesterol. ${ }^{25}$ Also, adiposity levels seem to highly track from childhood and adolescence to adulthood. ${ }^{26}$ Our results clearly state the role of higher physical fitness on attenuating adiposity development on those with genetic susceptibility to excess weight, which may lead to positive effects throughout life.

Physical fitness components can be improved via regular physical activity practice and exercise training, ${ }^{27}$ mainly by moderate to vigorous intensities. ${ }^{28,29}$ Also, intervention protocols demonstrate that decreased adiposity can be achieved by improving physical activity practice and aerobic capacity. ${ }^{30-32}$ Based on this knowledge, children and adolescents should accomplish the guidelines of 60 minutes of moderate to vigorous physical activity per day, whereas activities that improve muscular fitness should be engaged in at least three times per week. ${ }^{33}$ Furthermore, evidence indicates that improving physical fitness components during childhood and adolescence may improve overall health by reducing adiposity. ${ }^{34,35}$

The evidence regarding the associations between cardiovascular diseases during adulthood and higher adiposity during youth is established as evidenced by a longitudinal study with more than 1 million men. Here, the authors assessed CRF (via a maximum aerobic capacity workload test) and muscular fitness (determined by the knee extension, handgrip, and elbow flexion strength) in addition to BMI during adolescence and showed that better performance of these physical fitness components seems to attenuate the odds of suffering a cardiovascular disease disability later in life, independent of BMI classification. ${ }^{36}$ When considering the genetic influence in adults, the probability of obesity was attenuated by individuals who presented higher levels of aerobic capacity and muscular endurance (determined by the maximum number of abdominal crunches per minute). ${ }^{13}$

Our study should mention some limitations. The cross-sectional nature of the data does not allow to set conclusion about the direction of the association nor does it allow for causal inferences to be made. Also, the role of potential confounders, such as diet and physical activity were not considered. Finally, considering BMI as an adiposity parameter as it does not distinguish between fat mass and fat-free mass. Otherwise, the present study has 

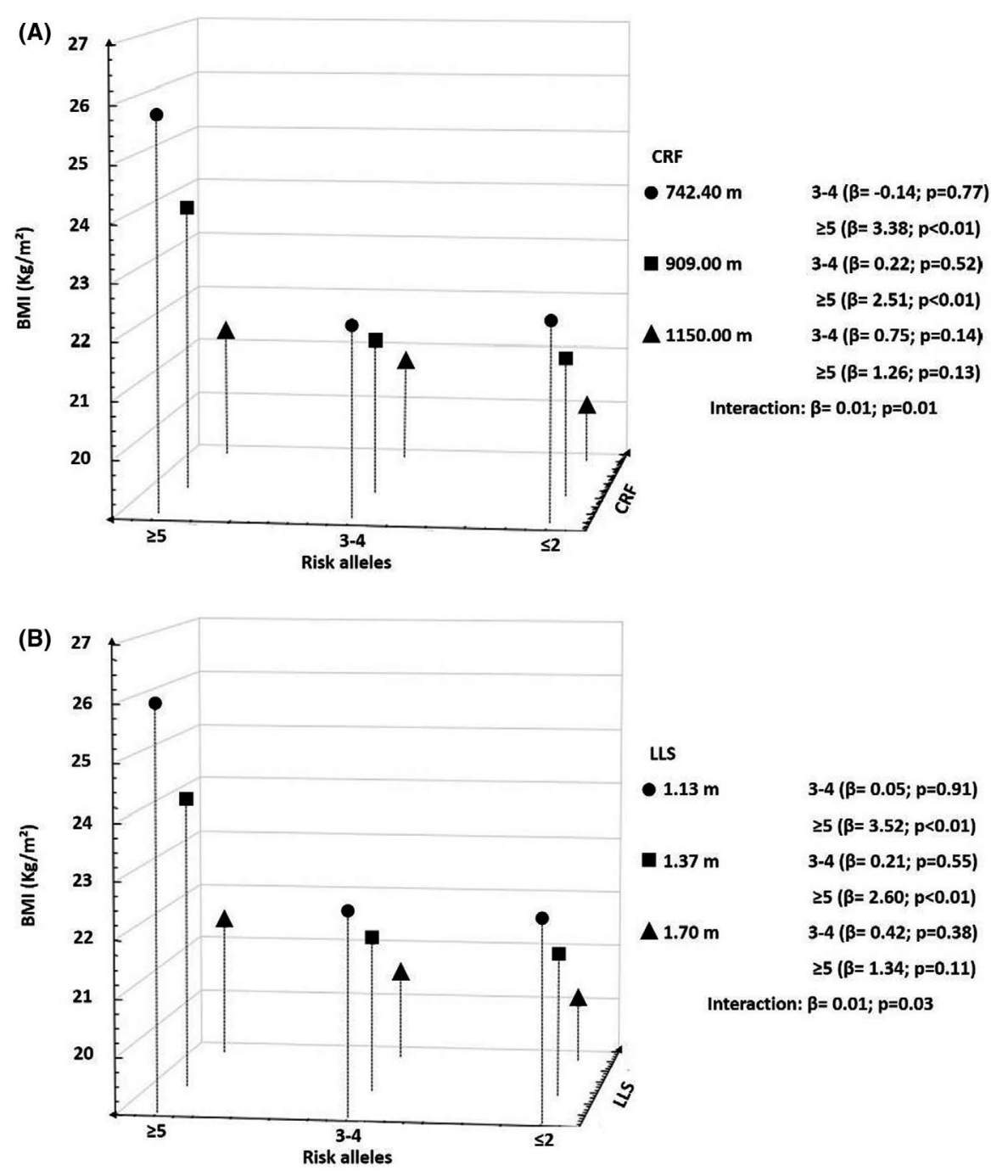

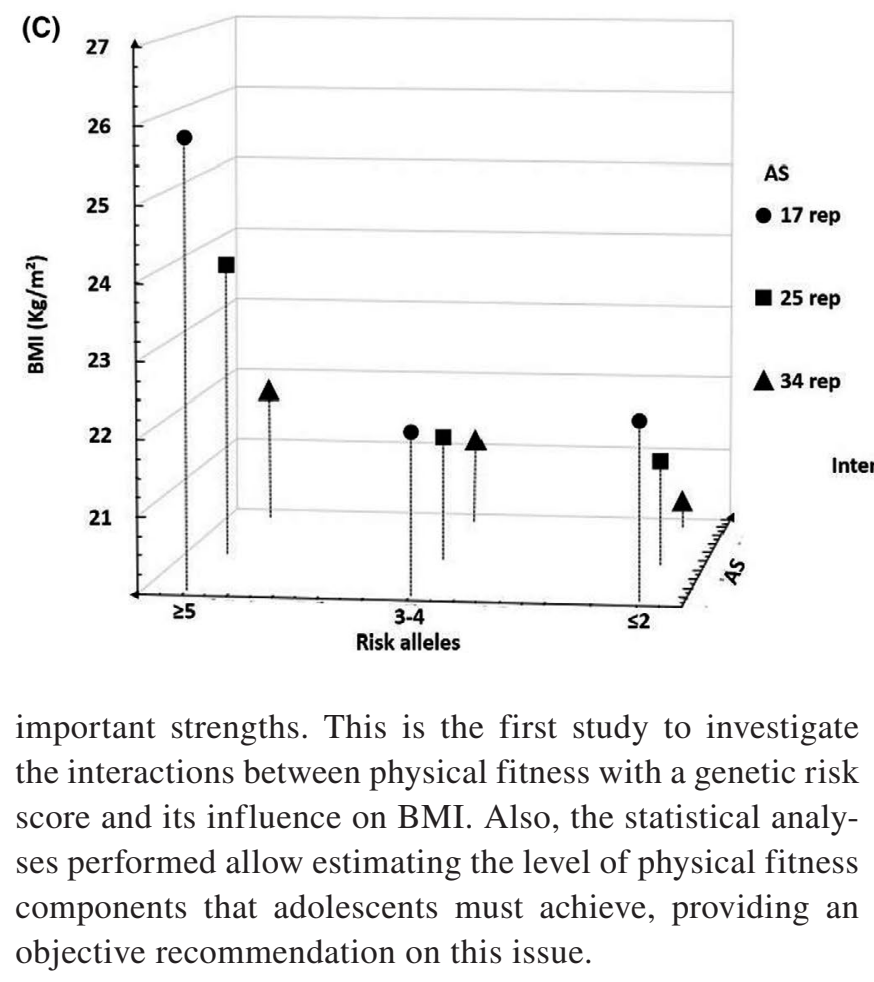

important strengths. This is the first study to investigate the interactions between physical fitness with a genetic risk score and its influence on BMI. Also, the statistical analyses performed allow estimating the level of physical fitness components that adolescents must achieve, providing an objective recommendation on this issue.

(B)

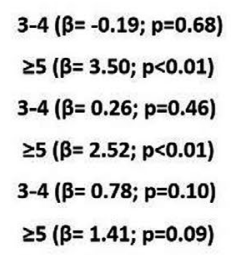

F IGURE 1 Moderation of cardiorespiratory fitness (A), lower limb strength (B), and abdominal strength (C) in the relationship between genetic risk alleles and BMI in adolescents. The category $\leq 2$ risk alleles were considered the reference group for all analyses. Abbreviations: AS, Abdominal strength; BMI, Body mass index; CRF, Cardiorespiratory fitness; LLS, Lower limb strength. All analyses were adjusted for sex, skin color/ethnicity, and sexual maturation

\section{5 | PERSPECTIVE}

Physical fitness components are biological traits that can attenuate higher BMI scores and improve the present and future overall health of children and adolescents. ${ }^{12}$ Thus, our findings highlight the need of achieving appropriate levels of 
physical fitness early in life, especially for those with a genetic predisposition to excess weight. In conclusion, physical fitness components (CRF, LLS, and abdominal strength) are moderators in the relationship between a genetic risk score and BMI in adolescents. These findings provide evidence that physical fitness patterns interact with genetic factors to influence BMI, highlighting the need for interventions targeting to improve this aspect, which is an important health indicator in all ages.

\section{ACKNOWLEDGMENTS}

This work was supported by the Higher Education Personnel Improvement Coordination-Brazil (CAPES) and the Brazilian National Research Council (CNPq).

\section{CONFLICT OF INTEREST}

The authors have no conflicts of interest.

\section{ORCID}

\section{Pâmela Ferreira Todendi (iD https://orcid. org/0000-0002-6091-4766} Caroline Brand (D) https://orcid.org/0000-0002-5624-3592 João Francisco de Castro Silveira (iD https://orcid. org/0000-0002-2231-759X

Anelise Reis Gaya (D) https://orcid. org/0000-0002-8335-6947 Cesar Agostinis-Sobrinho (iD https://orcid. org/0000-0001-9104-9042 Marilu Fiegenbaum (iD https://orcid. org/0000-0002-5408-2078 Ryan Donald Burns iD https://orcid. org/0000-0002-5933-4633 Andréia Rosane de Moura Valim (D) https://orcid. org/0000-0001-9611-3103

Cézane Priscila Reuter (D) https://orcid. org/0000-0002-4549-3959

\section{REFERENCES}

1. Lobstein T, Jackson-Leach R, Moodie ML, et al. Child and adolescent obesity: part of a bigger picture Tim. Lancet. 2015;385(9986):2510-2520.

2. Aggarwal B, Jain V. Obesity in children: definition, etiology and approach. Indian J Pediatr. 2017;85:1-9.

3. Campbell MK. Biological, environmental, and social influences on childhood obesity. Pediatr Res. 2016;79(1-2):205-211.

4. Francesquet M, Silva PTD, Schneiders LDB, et al. Youth overweight/obesity and its relationship with cardiovascular disease and parental risk factors. Arch Endocrinol Metab. 2019;63(4):411-416.

5. Li X, Keown-Stoneman CDG, Lebovic G, et al. The association between body mass index trajectories and cardiometabolic risk in young children. Pediatr Obes. 2020;15(8):1-11.

6. Uddin R, Lee EY, Khan SR, Tremblay MS, Khan A. Clustering of lifestyle risk factors for non-communicable diseases in 304,779 adolescents from 89 countries: a global perspective. Prev Med (Baltim). 2020;131:105955.

7. Mora-gonzalez J, Migueles JH, Esteban-cornejo I, et al. Sedentarism, physical activity, steps, and neurotrophic factors in obese children. Med Sci Sports Exerc. 2019;51(11):2325-2333.

8. Ferreira Todendi P, de Moura Valim AR, Klinger E, et al. The role of the genetic variants IRX3 rs3751723 and FTO rs9939609 in the obesity phenotypes of children and adolescents. Obes Res Clin Pract. 2019;13(2):137-142.

9. Jiang Y, Mei H, Lin Q, et al. Interaction effects of FTO rs9939609 polymorphism and lifestyle factors on obesity indices in early adolescence. Obes Res Clin Pract. 2019;13(4):352-357.

10. Ruiz JR, Labayen I, Ortega FB, et al. Attenuation of the effect of the FTO rs9939609 polymorphism on total and central body fat by physical activity in adolescents: the HELENA study. Arch Pediatr Adolesc Med. 2010;164(4):328-333.

11. Manco L, Pinho S, Albuquerque D, Machado-Rodrigues AM, Padez C. Physical activity and the association between the FTO rs 9939609 polymorphism and obesity in Portuguese children aged 3 to 11 years. Am J Hum Biol. 2019;31(6):1-8.

12. Ortega FB, Cadenas-Sanchez C, Lee D, Ruiz JR, Blair SN, Sui X. Fitness and Fatness as Health Markers through the Lifespan. Prog Prev Med. 2018;3(2):e0013.

13. Costa-Urrutia P, Abud C, Franco-Trecu V, et al. Genetic obesity risk and attenuation effect of physical fitness in MexicanMestizo population: a case-control study. Ann Hum Genet. 2017;81(3):106-116.

14. Egorova ES, Mustafina MM, Gabbasov RT, Borisova AV, Akhmetov II. Modifying effect of physical activity on genetic predisposition to obesity. Ter Arkh. 2014;86(10):36-39.

15. Katus U, Villa I, Ringmets I, et al. Association of FTO rs 1421085 with obesity, diet, physical activity, and socioeconomic status: a longitudinal birth cohort study. Nutr Metab Cardiovasc Dis. 2020;30(6):948-959.

16. dos Santos SA. Historical roots of the "Whitening" of Brazil. Lat Am Perspect. 2002;29(1):61-82.

17. Parra FC, Amado RC, Lambertucci JR, Rocha J, Antunes CM, Pena SDJ. Color and genomic ancestry in Brazilians. Proc Natl Acad Sci USA. 2003;100(1):177-182.

18. Tanner JM. Normal growth and techniques of growth assessment. Clin Endocrinol Metab. 1986;15(3):411-451.

19. Gaya A, Gaya AR. Manual de aplicação de medidas e testes, normas e critérios de avaliação. 2016. https://www.ufrgs.br/proesp/. Accessed October 31, 2020

20. Gaya AR, Dias AF, Lemes VB, et al. Aggregation of risk indicators to cardiometabolic and musculoskeletal health in Brazilian adolescents in the periods 2008/09 and 2013/14. J Pediatr (Rio J). 2018;94(2):177-183.

21. Gaya AR, Mello JB, Dias AF, et al. Temporal trends in physical fitness and obesity among Brazilian children and adolescents between 2008 and 2014. J Hum Sport Exerc. 2019;15(3):549-558.

22. Miller SA, Dykes DD, Polesky HF. A simple salting out procedure for extracting DNA from human nucleated cells. Nucleic Acids Res. 1988;16(3):1215.

23. Todendi PF, Klinger EI, Geraldo ACR, et al. Genetic risk score based on fat mass and obesity-associated, transmembrane protein 18 and fibronectin type III domain containing 5 polymorphisms is associated with anthropometric characteristics in South Brazilian children and adolescents. Br J Nutr. 2019;121(1):93-99. 
24. Kathiresan S, Melander O, Anevski D, et al. Polymorphisms associated with cholesterol and risk of cardiovascular events. $N$ Engl J Med. 2008;358(12):1240-1249.

25. Umer A, Kelley GA, Cottrell LE, Giacobbi P, Innes KE, Lilly CL. Childhood obesity and adult cardiovascular disease risk factors: a systematic review with meta-analysis. BMC Public Health. 2017;17(1):683.

26. Singh AS, Mulder C, Twisk JWR, Van Mechelen W, Chinapaw MJM. Tracking of childhood overweight into adulthood: a systematic review of the literature. Obes Rev. 2008;9(5):474-488.

27. Oliveira L, Braga F, Lemes V, et al. Effect of an intervention in Physical Education classes on health related levels of physical fitness in youth. Rev Bras Atividade Física Saúde. 2017;22(1):46-53.

28. Costigan SA, Eather N, Plotnikoff RC, Taaffe DR, Lubans DR. High-intensity interval training for improving health-related fitness in adolescents: a systematic review and meta-analysis. Br J Sports Med. 2015;49(19):1253-1261.

29. Beltran-Valls MR, Adelantado-Renau M, Moliner-Urdiales D. Reallocating time spent in physical activity intensities: Longitudinal associations with physical fitness (DADOS study). $J$ Sci Med Sport. 2020.

30. Kriemler S, Zahner L, Schindler C, et al. Effect of school based physical activity programme (KISS) on fitness and adiposity in primary schoolchildren: cluster randomised controlled trial. BMJ. 2010;340:c785.

31. Kühr P, Lima RA, Grøntved A, Wedderkopp N, Klakk H. Three times as much physical education reduced the risk of children being overweight or obese after 5 years. Acta Paediatr Int J Paediatr. 2020;109(3):595-601.
32. Lima RA, Andersen LB, Soares FC, Kriemler S. The causal pathway effects of a physical activity intervention on adiposity in children: the KISS Study cluster randomized clinical trial. Scand J Med Sci Sports. 2020;15360785:1-7.

33. ACSM. American College of Sports Medicine. ACSM's Guidelines for Exercise Testing and Prescription. Philadelphia: Wolters Kluwer; 2017.

34. García-Hermoso A, Ramírez-Campillo $\mathrm{R}$, Izquierdo $\mathrm{M}$. Is Muscular fitness associated with future health benefits in children and adolescents? a systematic review and meta-analysis of longitudinal studies. Sport Med. 2019;49:1-16.

35. Mintjens S, Menting MD, Daams JG, van Poppel MNM, Roseboom TJ, Gemke RJBJ. Cardiorespiratory fitness in childhood and adolescence affects future cardiovascular risk factors: a systematic review of longitudinal studies. Sport Med. 2018;48(11):2577-2605.

36. Henriksson H, Henriksson P, Tynelius P, et al. Cardiorespiratory fitness, muscular strength, and obesity in adolescence and later chronic disability due to cardiovascular disease : a cohort study of 1 million men. Eur Heart J. 2020;41:1503-1510.

How to cite this article: Todendi PF, Brand C, Silveira JFDC, et al. Physical fitness attenuates the genetic predisposition to obesity in children and adolescents. Scand J Med Sci Sport. 2021;31:894902. https://doi.org/10.1111/sms.13899 